\title{
Pregnancy rates and births after unilateral or bilateral transfer of bovine embryos produced in vitro
}

\author{
H. D. Reichenbach, J. Liebrich, U. Berg and G. Brem \\ Department of Molecular Animal Breeding, Ludwig-Maximilian University, 8000 München 22, \\ Germany
}

\begin{abstract}
Summary. Late morulae and blastocysts produced in vitro were nonsurgically transferred to heifers by unilateral $(n=184)$ or bilateral $(n=94)$ transfer. Of the recipients, $58 \%$ had serum progesterone values $>1.4 \mathrm{ng} \mathrm{ml}^{-1}$ on day 21 and rectal palpation on day 35 showed that $50 \%$ (138 of 278 ) were pregnant. The embryonic mortality rate between days $2 \mathrm{I}$ and 35 was estimated to be about $14 \%$ and between days 36 and 90 to be about $12 \%$. Of the animals, $8 \%$ aborted between days 91 and 250 of pregnancy. No difference was observed in pregnancy rates between unilateral transfer of one $(47 \%)$ or two embryos $(49 \%)$ and bilateral transfer $(53 \%)$, or in the twinning rate between bilateral transfer $(42 \%)$ and unilateral transfer of two embryos $(33 \%)$. The pregnancy rate was $54 \%$ with embryos evaluated as morphologically excellent or good, $51 \%$ with fair embryos and $26 \%$ with poor ones. A higher pregnancy rate $(60 \%)$ was obtained after embryo transfer when the synchrony between recipient and embryo was -1 day.
\end{abstract}

Keywords: in vitro; embryo transfer; pregnancy; cow

\section{Introduction}

Births of calves resulting from oocytes matured in vivo (Brackett et al., 1982; Sirard et al., 1985) or in vitro (Critser et al., 1986; Utsumi et al., 1988) and fertilized in vitro were first obtained after in vivo culture of the resulting zygotes in oviducts of intermediate animals before embryo transfer to final recipients. In the last few years, methods for in vitro culture of early embryo stages from oocytes matured and fertilized in vitro (IVM-IVF) using suitable cell culture systems have been established and pregnancies have resulted from transfer of the embryos produced in vitro to recipients (Goto et al., 1988; Eyestone \& First, 1989; Kajihara et al., 1990; Lu et al., 1990; Xu et al., 1990). These new methods have many advantages over the in vivo methods; for example, they are less expensive, and provide the possibility of producing a high number of embryos, making it possible to evaluate and manipulate the embryos during development. This opens up many possibilities for correlative studies, such as raising clones, the transfer of genes and the detailed study of early embryonic development (Leibfried-Rutledge et al., 1989; Rexroad, 1989; Gagné et al., 1990). These methods also make it possible to produce calves from superior cows with interesting traits, but which are infertile for nongenetic reasons (Shea et al., 1983). Development rates of IVM-IVF bovine oocytes in different cell culture systems have been described in previous reports (Berg \& Brem, 1989, 1990). The present study determined the pregnancy results after transfer of morulae and blastocysts to a large number of recipients and evaluated their competence to develop to term. 


\section{Materials and Methods}

\section{Recipient animals}

Nulliparous crossbred German Simmental and crossbred Friesian heifers, about 15-18 months old and 350-550 kg, were kept in groups of six to nine animals per lot without access to exercise lots. They were fed maize or grass silage, sweet feed ad libitum. The animals had free access to water and salt-mineral licking stones.

Signs of oestrus, such as standing to be mounted, mounting other heifers and other behavioural signs, were monitored twice a day (dawn and dusk). Synchronization was either performed by a single intramuscular injection of $500 \mu \mathrm{g}$ cloprostenol (Estrumate: Coopers, Burgwedel, Germany), administered in the midluteal phase, or by a progesterone-releasing intravaginal device (PRID; Abbovestrol: Sanofi, Düsseldorf, Germany), which was placed in the vagina for 12 days, regardless of stage of the oestrous cycle. The onset of oestrus (day 0 ) was defined as the period in which the heifers first stood to be mounted by other heifers or showed other behavioural signs of oestrus.

\section{Production of embryos}

The IVM-IVF and co-culture system was described by Berg \& Brem $(1989,1990)$. Ovaries of nonpregnant animals were obtained by slaughter, and follicles with a diameter of $2-6 \mathrm{~mm}$ were punctured to collect cumulus-oocyte complexes. Oocytes with a complete dense cumulus oophorus and dark evenly granulated cytoplasm were matured for approximately $24 \mathrm{~h}$ at $39^{\circ} \mathrm{C}$ in TCM 199 medium supplemented with $2.00 \mathrm{mmol}$ sodium pyruvate $\mathrm{l}^{-1}, 2.92 \mathrm{mmol}$ calcium lactate $1^{-1}, 10 \mu \mathrm{g}$ follicle-stimulating hormone (FSH-P; Schering, Kenilworth, NJ, USA) $\mathrm{ml}^{-1}$, in a Hepescarbonate buffer system $\left(4.43 \mathrm{mmol}\right.$ Hepes and $33.90 \mathrm{mmol}$ sodium bicarbonate $\left.\mathrm{l}^{-1}\right)$, containing $60 \mu \mathrm{g}$ gentamycin $\mathrm{ml}^{-1}$ and $20 \%$ heat-inactivated oestrous cow serum. IVF (day 0 ) was achieved using frozen-thawed semen $\left(10^{6}\right.$ spermatozoa $\mathrm{ml}^{-1}$ ) which had been subjected to a swim-up procedure described by Parrish et al. (1986). The IVF medium consisted of a Tyrode's solution (TALP) modified as described by Barister \& Yanagimachi (1977) and supplemented with $0.6 \%$ bovine serum albumin, $1 \mu$ mol epinephrine $1^{-1}, 10 \mu$ mol hypotaurine $1^{-1}$ and $10 \mu \mathrm{g} \mathrm{heparin} \mathrm{ml}{ }^{-1}$ (Ball et al., 1983). The incubation time was about $20 \mathrm{~h}$. The culture conditions for IVM-IVF consisted of $5 \% \mathrm{CO}_{2}$ in air of maximum humidity. The embryos were subsequently cultured for about 6 days at $39^{\circ} \mathrm{C}$ under paraffin oil in four-well tissue-culture plates (Nunc, Roskilde, Denmark) in TCM 199 (as for the IVM medium but without folliclestimulating hormone) in $5 \% \mathrm{CO}_{2}, 5 \% \mathrm{O}_{2}$ and $90 \% \mathrm{~N}_{2}$. Granulosa cells from the cumulus grew into a cell layer within a short time.

\section{Embryo transfer}

On day 7 after IVF (day 0 ), the culture plates containing the co-culture medium and the embryos were transported (for about $2 \mathrm{~h}$ ) to the recipients in a thermo-cell-transporter (Labotect, Göttingen, Germany) at $37^{\circ} \mathrm{C}$ in $5 \% \mathrm{CO}_{2}, 5 \%$ $\mathrm{O}_{2}$ and $90 \% \mathrm{~N}_{2}$. Embryos that had reached the late morula and blastocyst stage by this time were evaluated by morphological criteria and graded as excellent (spherical, symmetrical with cells of uniform size, colour and texture), good (trivial imperfections, such as a few extruded blastomeres, irregular shape, few vesicles), fair (presence of extruded blastomeres, vesiculation, few degenerated cells) or poor (numerous extruded blastomeres, degenerated cells, cells of differing size, large numerous vesicles, but an embryo mass of viable appearance) by light microscopy (Lindner \& Wright, 1983). Embryos selected were washed three times in phosphate-buffered saline medium supplemented with $0.4 \%$ bovine serum albumin and transferred non-surgically to synchronous or asynchronous recipients. The synchrony between the age of the transferred embryo and the day of the oestrous cycle of the recipient was evaluated by assuming that late morulae were in synchrony with day 6 recipients and that blastocysts were in synchrony with day 7 recipients.

Heifers were only selected as recipients if they showed signs of oestrus, had a functional corpus luteum and were free of cystic ovarian follicles and genital abnormalities detectable by palpation per rectum.

All recipients were tranquillized by an intramuscular injection of acepromazin-maleate (Vetranquil: Albrecht, Aulendorf, Germany) and received epidural anaesthesia (Lidocain: Chassot, Ravensburg, Germany) 5-10 min before embryo transfer. They were treated with clenbuterolhydrochloride (Planipart: Boehringer, Ingelheim, Germany), for relaxation of the uterus. A sterile embryo transfer gun $(0.25 \mathrm{ml}$ straw), ensheathed in a sterile nylon film (Chemise Sanitaire: France) was passed into the vagina and, when next to the cervix, the sheath was retracted and the gun was advanced through the cervix. One or two embryos, depending on the availability of embryos each day, were deposited in the uterine horn ipsilateral to the corpus luteum (unilateral transfer of one or two embryos) or in both horns (bilateral embryo transfer). During unilateral or bilateral twin transfers, one embryo of higher quality was transferred with an embryo of lesser quality. In bilateral transfers, the higher-quality embryo was always deposited ipsilateral to the functional corpus luteum.

\section{Pregnancy diagnosis}

Heifers that did not show oestrus after embryo transfer underwent pregnancy tests, determined by radioimmunoas say of plasma progesterone concentration on day 21 and palpation per rectum on day 35 . Heifers were diagnosed 
as pregnant when concentrations of progesterone in plasma on day 21 were $>1.4 \mathrm{ng} \mathrm{ml}^{-1}$ (reference value) and paipation was positive on day 35 . Heifers that failed to become pregnant after three consecutive embryo transfers were excluded from the study. Data were statistically analysed by the $\chi^{2}$ test.

\section{Results}

\section{Pregnancies}

Of 278 recipients of embryos, $161(58 \%)$ had progesterone values $>1.4 \mathrm{ng} \mathrm{ml}^{-1}$ on day 21 (Table 1); ten of them showed oestrus between days 28 and 35; 13 did not show visible signs of oestrus within this time, but palpation on day 35 was negative: the remaining $138(50 \%)$ heifers were pregnant by the time of the first examination per rectum (day 35). The embryonic mortality rate between days 21 and 35 was estimated as about 14\%, from the results. The number of pregnancies was reduced to $121(44 \%)$ by the time of the second examination (day 90$)$. Embryonic mortality rate between days 36 and 90 was about $12 \%$. Eleven $(8 \%)$ more recipients aborted between days 91 and 250 of gestation.

The abortion rate (days 91-250) after unilateral transfer of two embryos $(22 \%, 6$ of 27$)$ was higher $(P<0.05)$ than after unilateral transfer of single embryos $(3 \%, 2$ of 61$)$ or after bilateral transfer $(6 \%, 3$ of 50$)$. After unilateral transfer of two embryos, nine twin pregnancies were produced, but only one set of twins developed to term; the other eight recipients aborted, six of them between days 91 and 250 .

There were no differences in pregnancy rates (day 35) between the ipsilateral transfer of one embryo $(47 \%, 61$ of 129$)$, unilateral twin embryo transfer $(49 \%, 27$ of 55$)$ or bilateral transfer $(53 \%, 50$ of 94$)$. The twinning rate for ipsilateral transfers $(33 \%, 9$ of 27$)$ was lower than, but not different from, that for bilateral transfers $(42 \%, 21$ of 50$)$. In the group of recipients that received single embryos, one animal gave birth to monozygotic twins.

Embryos were produced in vitro each week over a long period. It was, therefore, possible to transfer embryos every week and to include animals that had failed to become pregnant, as subsequent recipients 21 days later, without having to resynchronize them. These recipients showed lower pregnancy rates $(P<0.05,37 \%, 13$ of 35$)$ than animals synchronized with PRID $(58 \%$, 36 of 62$)$ or cloprostenol-treated heifers $(49 \%, 89$ of 181). Animals that failed twice to become pregnant showed lower pregnancy rates $(39 \%, 14$ of 36$)$ than animals that failed once $(46 \%, 44$ of $96)$ or recipients that became pregnant with the first embryo transfer (55\%, 80 of 146). Differences in pregnancy success also resulted after unilateral transfer of one embryo in the late morula (39\%, 10 of 26$)$, early blastocyst $(43 \%, 6$ of 14$)$, blastocyst $(49 \%, 31$ of 63$)$ or expanded blastocyst stage $(54 \%, 14$ of 26$)$.

A higher $(P<0.05)$ pregnancy rate (day 35) was observed after embryo transfer when the relative synchrony between recipient and embryo was -1 day $(60 \%, 31$ of 52) compared with +1 day $(30 \%, 9$ of 30; Table 2). Pregnancy rates attained were $54 \%$ with morphologically excellent or good embryos, $51 \%$ with fair embryos, and $26 \%$ with poor embryos $(P<0.05)$.

\section{Births and calves}

A total of 110 full-term or nearly full-term pregnancies was produced. The first successful pregnancy ended in the abortion of a female fetus, 254 days after embryo transfer. In July 1989, the first recipient came to term and delivered a male calf. More than 80 calves have now been born, among them ten sets of twins. One calf was born with paresis affecting the hind limbs, but fractures or congenital abnormalities could not be identified by clinical examination. All other calves appeared to be normal at birth. The length of gestation for single pregnancies ranged from 276 to 304 days. Gestation was 11 days shorter for twin-calving animals. Newborn male calves represented $56 \%$ of the births. Twin-calf birth weight (mean $\pm \mathrm{SD}, 36 \pm 9 \mathrm{~kg}$ ) was lower than, but not different from, that of single calves $(46 \pm 6 \mathrm{~kg})$; single male $(48 \pm 5 \mathrm{~kg})$ and single female 


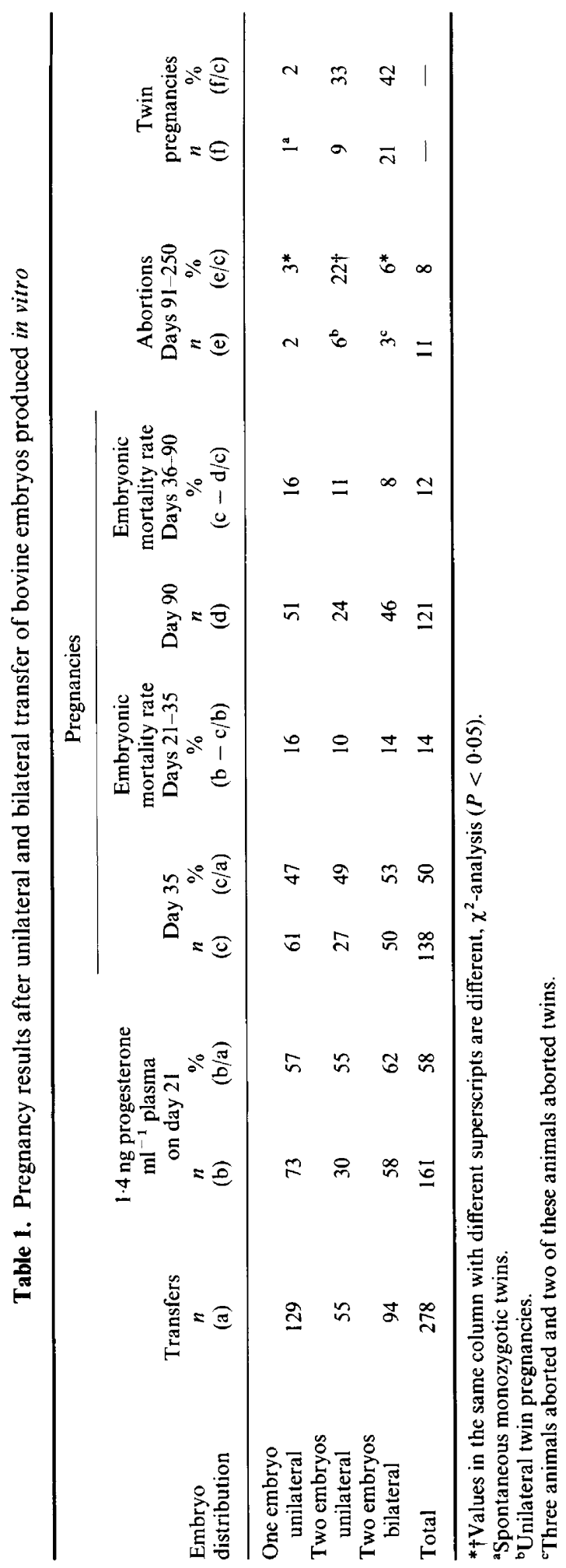


Table 2. Effect of recipient and embryo synchrony and morphological quality on pregnancy rates $(\%)$ after unilateral transfer of one bovine embryo produced in vitro

\begin{tabular}{lccccc}
\hline & \multicolumn{4}{c}{ Recipient embryo synchrony (days) } & \\
\cline { 2 - 5 } Embryo quality & -2 & -1 & 0 & +1 & Total \\
\hline Excellent or good & $50(2 / 4)$ & $63(19 / 30)$ & $47(9 / 19)$ & $38(3 / 8)$ & $54(33 / 61)^{\mathrm{a}}$ \\
Fair & - & $65(11 / 17)$ & $50(7 / 14)$ & $30(3 / 10)$ & $51(21 / 41)$ \\
Poor & $0(0 / 2)$ & $20(1 / 5)$ & $38(3 / 8)$ & $25(3 / 12)$ & $26(7 / 27)^{\mathrm{b}}$ \\
Total & $33(2 / 6)$ & $60(31 / 52)^{\mathrm{a}}$ & $46(19 / 41)$ & $30(9 / 30)^{\mathrm{b}}$ & $47(61 / 129)$ \\
\hline
\end{tabular}

a.bValues in the same column or line with different superscripts are significantly different $(P<0.05)$.

$(43 \pm 6 \mathrm{~kg})$ calves had similar birth weights. Dystocia or difficult births were not observed in heifers producing twins, but calving assistance was necessary in many animals that delivered single calves. Assistance to 12 of these births involved Caesarean section and one stillbirth was registered. Birth weight of calves born after Caesarean section was $52 \pm 6 \mathrm{~kg}$. More (nine) single calves died during or soon after a difficult delivery that did not involve Caesarean section.

\section{Discussion}

Pregnancies and birth of live offspring have been established by the transfer of the embryos derived from our previously reported in vitro culture system. The results confirm earlier reports of satisfactory pregnancy rates following transfer of embryos produced in vitro (Goto et al., 1988; Eyestone \& First, 1989; Lu et al., 1990; Xu et al., 1990; Yang et al., 1991).

The overall pregnancy rate (day 35 ) in the present study was $50 \%$. The accuracy of the determination of plasma progesterone on day 21 for detecting pregnancy was $86 \%$. Failure of pregnancy could be confirmed in $100 \%$ of the recipients that had $<1.4 \mathrm{ng}$ progesterone $\mathrm{ml}^{-1}$ on day 21. It is concluded that determination of plasma progesterone on day 21 is a satisfactory method for distinguishing between non-pregnant and pregnant animals after embryo transfer and can be used to identify animals included 21 days later as subsequent recipients, without having to resynchronize them.

The extent of embryonic mortality occurring between day 21 and day 35 was estimated as the number of non-pregnant recipients with $>1.4 \mathrm{ng}$ progesterone $\mathrm{ml}^{-1}$ on day 21 . These animals (14\%) showed abnormally long cycles and some of them possibly had an apparent silent or missed oestrus. Extended cycle length may occur for a variety of reasons, including endocrine, environmental, genetic and intrinsic embryonic factors (Sreenan \& Diskin, 1983, 1987; King, 1985). Embryonic mortality rate estimated on the basis of cycle length therefore only provides limited evidence of the real extent of embryonic death after embryo transfer. A certain rate of embryonic loss is expected after embryo transfer, regardless of the kind of manipulation that has been applied to the embryos (Heyman, 1985; King, 1985). Embryonic loss after transfer was estimated to be $14 \%$ between days 21 and 35 and $12 \%$ between days 35 and 90 . These results are in accord with those reported in other studies involving the transfer of non-manipulated embryos from superovulated donors (Jillella \& Baker, 1978; Christie et al., 1980; Renard et al., 1980; Heyman, 1985). It can be concluded, therefore, that transfer of embryos produced in vitro does not significantly increase the embryo mortality rate expected when non-manipulated embryos are transferred to recipients.

The pregnancy rates (day 35) achieved after unilateral transfer of two embryos to the uterine horn ipsilateral to the corpus luteum $(49 \%)$ or after bilateral transfer of single embryos to each uterine horn $(53 \%)$ were not different from that observed after unilateral transfer of single embryos 
$(47 \%)$. Although the transfer of an additional embryo to the ipsilateral or contralateral uterine horn did not decrease the pregnancy rate obtained after unilateral transfer of single embryos, the abortion rate was higher after the unilateral transfer of two embryos $(22 \%)$ than after unilateral transfer of single embryos (3\%) or after bilateral transfer $(6 \%)$. After the unilateral transfer of two embryos, only one twin-pregnancy came to term. The remaining recipients aborted twins, in most cases during the last third of gestation. Rowson et al. (1971) suggested that competition between embryos within a single uterine horn seemed to occur after unilateral transfer of two embryos. Rowson et al. (1972) indicated that, because transuterine migration rarely occurs in cattle, embryonic death after unilateral transfer of two embryos results simply from overcrowding in the one horn. Bellows et al. (1974) proposed that a higher twinning rate could perhaps be achieved from multiparous cows than from virgin heifers. The high occurrence of twin-aborts after unilateral transfer of two embryos observed in our study corroborates this idea. For the production of twin calves, bilateral transfer is therefore preferable over unilateral twin transfer, especially when heifers are used as recipients.

The twinning rates ( 33 and $42 \%$ ) were low compared with results obtained with bilateral surgical transfer of embryos produced in vivo (Rowson et al., 1971; Sreenan et al., 1975, 1978; Anderson et al., 1978) and with that reported after unilateral transfer of two embryos (Boland et al., 1975; Testart et al., 1975). Similar twinning rates were reported by Newcomb et al. (1978) after surgical transfer of an embryo to one uterine horn and non-surgical transfer to the other, and by Yang et al. (1991) after twin-transfer of embryos produced in vitro. A low twinning rate was expected in our study because embryos of varying quality (and therefore viability) were transferred together. More meaningful results would have been generated by restricting twin-transfers to excellent or good embryos only. One recipient gave birth to monozygotic twins, even though only one embryo was transferred to this animal. The birth of monozygotic twins following the transfer of single embryos obtained from superovulated cows was also reported by King et al. (1985).

A higher $(60 \%)$ pregnancy rate was achieved following embryo transfer when the relative synchronicity between recipient and embryo was -1 day (Table 2). Kajihara et al. (1990) obtained higher pregnancy rates after transfer of embryos produced in vitro to asynchronous recipients. However, the achievement of higher rates after embryo transfer to -2 days asynchronous recipients was not confirmed in our study. Embryos produced in vivo and collected from the uterus of superovulated donors should be returned to the uterus of recipients at approximately the same stage in their oestrous cycle as the donors (Rowson et al., 1969; Hasler et al., 1987). Our results for the transfer of embryos produced in vitro suggest that these embryos develop more slowly than those conceived in vivo and should therefore be transferred to -1 day asynchronous recipients.

Embryo evaluation to select the most viable for transfer is practised routinely in embryo transfer programmes. A difference in pregnancy rates occurred when excellent or good, as opposed to fair or poor quality, embryos recovered from superovulated donor cows were transferred (Shea, 1981; Lindner \& Wright, 1983; King et al., 1985; Hasler et al., 1987). The transfer of embryos produced in vitro evaluated as morphologically excellent, good or fair, resulted in a higher pregnancy rate than the transfer of poor embryos (Table 2).

Animals that fail to become pregnant after embryo transfer are usually used repeatedly as recipients. In the present study, the pregnancy rates in previously failed recipients was lower than after first transfer. The post-transfer survival rate of embryos depends on the interaction between intrinsic factors that are known to affect the embryo adversely, such as chromosome abnormalities, and extrinsic factors, such as the recipients themselves (King, 1985). The lowered pregnancy rates for second and third transfers were, therefore, not always due to the infertility of such recipients.

The satisfactory pregnancy rate obtained with PRID-synchronized heifers $(58 \%)$, which was higher than that obtained with cloprostenol-synchronized animals (49\%), suggests that PRID provides an efficient means of synchronizing oestrus in recipients. However, the device was not always simple to administer to heifers and different degrees of vaginitis were observed. There were 
no attempts to cleanse these vaginal secretions before embryo transfer. The use of sterile nylon film (Chemise Sanitaire) to cover the embryo transfer gun in the vagina up to penetration of the cervix may have prevented infection of the uterus.

There are many other factors that influence post-transfer embryo survival rate: some of these are intrinsic to the embryo itself or acquired during in vitro manipulations (Heyman, 1985; Sreenan \& Diskin, 1987; Berg \& Brem, 1990). The results of the present study indicated that satisfactory pregnancy results can be obtained when excellent, good or fair embryos, derived from previously reported in vitro culture systems, are transferred to -1 day asynchronous recipients.

The authors are grateful to T. Holy for technical assistance, J. Brem for assistance with the pregnant animals and to I. Janka for suggestions in the preparation of the manuscript.

\section{References}

Anderson, P., Cupps, T., Drost, M., Horton, M.B. \& Wright, R.W. (1978) Induction of twinning in beef heifers by bilateral embryo transfer. Journal of Animal Science 46, 449-452.

Ball, G.D., Leibfried, M.L., Lenz, R.L., Ax, R.L., Bavister, B.D. \& First, N.L. (1983) Factors affecting successful in vitro fertilization of bovine follicular oocytes. Biology of Reproduction 28, 717-725.

Bavister, B.D. \& Yanagimachi, R. (1977) The effects of sperm extract and energy sources on the motility and acrosome reaction of hamster sperm in vitro. Biology of Reproduction 16, 228-237.

Bellows, R.A., Short, R.E., Urick, J.J. \& Pahnish, O.F. (1974) Effects of early weaning on post-partum reproduction of the dam and growth of calves born as multiples or singles. Journal of Animal Science 39, $589-593$.

Berg, U. \& Brem, G. (1989) In-vitro production of bovine blastocysts by in-vitro maturation and fertilization of oocytes and subsequent in-vitro culture. Zuchthygiene 24, $134-139$.

Berg, U. \& Brem, G. (1990) Developmental rates of in vitro produced IVM-IVF bovine oocytes in different cell co-culture systems. Theriogenology 33, 195.

Boland, M.P., Crosby, T.F. \& Gordon, I. (1975) Twin pregnancy in cattle established by nonsurgical egg transfer. British Veterinary Journal 131, 738-740.

Brackett, B.G., Bousquet, D., Boice, M.L., Donawick, W.J., Evans, J.F. \& Dressel, M.A. (1982) Normal development following in vitro fertilization in the cow. Biology of Reproduction 27, 147-158.

Christie, W., Newcomb, R. \& Rowson, L.E.A. (1980) Non-surgical transfer of bovine eggs: investigation of some factors affecting embryo survival. Velerinary Record 106, 190-193.

Critser, E.S., Leibfried-Rutledge, M.L., Eyestone, W.H., Northy, D.L. \& First, N.L. (1986) Acquisition of developmental competence during maturation in vitro. Theriogenology 25, 150.

Eyestone, W.H. \& First, N.L. (1989) Co-culture of early cattle embryos to the blastocyst stage with oviducal tissue or in conditioned medium. Journal of Reproduction and Fertility 85, 715-720.

Gagné, M., Pothier, F. \& Sirard, M.A. (1990) Developmental potential of early bovine zygotes submitted to centrifugation and microinjection following in vitro maturation of oocytes. Theriogenology 34, 417-425.
Goto, K., Kajihara, Y., Kosaka, S., Koba, M., Nakanishi, Y. \& Ogawa, K. (1988) Pregnancies after co-culture of cumulus cells with bovine embryos derived from in vitro fertilization of in vitro matured follicular oocytes. Journal of Reproduction and Fertility 83, $753-758$.

Hasler, J.F., McCauley, A.D., Lathrop, W.P. \& Foote, R.H. (1987) Effect of donor-embryo-recipient interactions on pregnancy rate in a large scale bovine embryo transfer program. Theriogenology 27 , $139-168$.

Heyman, Y. (1985) Factors affecting the survival of whole and half-embryos transferred in cattle. Theriogenology 23, 63-75.

Jillella, D. \& Baker, A.A. (1978) Transcervical transfer of bovine embryos. Veterinary Record 103, 574-576.

Kajihara, Y., Kometani, N., Kobayashi, S., Shitanaka, Y., Koshiba, Y., Hishiyama, K., Shiraiwa, K. \& Goto, K. (1990) Pregnancy rates and births after co-culture of cumulus cells with bovine embryos derived from in vitro fertilization of in-vitro matured follicular oocytes. Theriogenology 33, 264.

King, K.K., Seidel, G.E. Jr \& Elsden, R.P. (1985) Bovine embryo transfer and pregnancies. I. Abortion rates and characteristics of calves. Journal of Animal Science 61, 747-757.

King, W.A. (1985) Intrinsic embryonic factors that may affect survival after transfer. Theriogenology 23, 161-174.

Leibfried-Rutledge, M.L., Critser, E.S., Parrish, J.J. \& First, N.L. (1989) In vitro maturation and fertilization of bovine oocytes. Theriogenology 31, 61-74.

Lindner, G.M. \& Wright, R.W. (1983) Bovine embryo morphology and evaluation. Theriogenology $\mathbf{2 0}$, $407-416$.

Lu, K.H., Jiang, H.S., Wang, W.L. \& Cordon, I. (1990) Pregnancies established in cattle by transfer of fresh and frozen embryos derived from in-vitro maturation and fertilization of oocytes and their subsequent culture in vitro. Theriogenology 33, 278.

Newcomb, R., Christie, W.B. \& Rowson, L.E.A. (1978) Comparison of the fetal survival rate in heifers after the transfer of an embryo surgically to one uterine horn and non-surgically to the other. Journal of Reproduction and Fertility 52, 395-397.

Parrish, J.J., Susko-Parrish, J.L., Leibfried-Rutledge, M.L., Critser, E.S., Eyestone, W.H. \& First, N.L. 
(1986) Bovine in vitro fertilization with frozenthawed semen. Theriogenology 25, 591-600.

Renard, J.P., Heyman, Y. \& Ozil, J.P. (1980) Importance of gestation losses after non-surgical transfer of cultured and non cultured bovine blastocysts. Veterinary Record 107, 152-153.

Rexroad, C.E. Jr (1989) Co-culture of domestic animal embryos. Theriogenology 31, 105-114.

Rowson, L.E.A., Moor, R.M. \& Lawson, R.A.S. (1969) Fertility following egg transfer in the cow: effect of method, medium and synchronization of oestrus. Journal of Reproduction and Fertility 18, 517-523.

Rowson, L.E.A., Lawson, R.A.S. \& Moor, R.M. (1971) Production of twins in cattle by egg transfer. Journal of Reproduction and Fertility 25, 261-268.

Rowson, L.E.A., Lawson, R.A.S., Moor, R.M. \& Baker, A.A. (1972) Egg transfer in the cow: synchronization requirements. Journal of Reproduction and Fertility 28, $427-432$.

Shea, B.F. (1981) Evaluating the bovine embryo. Theriogenology 15, 31-42.

Shea, B.F., Jansen, R.E. \& McAlister, R. (1983) Recovery and fertilization of bovine follicular oocytes. Theriogenology 19, 385-390.

Sirard, M.A., Lambert, R.D., Menard, D.P. \& Bedoya, M. (1985) Pregnancies after in-vitro fertilization of cow follicular oocytes, their incubation in rabbit oviducts and their transfer to the cow uterus. Journal of Reproduction and Fertility 75, 551-556.

Sreenan, J.M. \& Diskin, M.G. (1983) Early embryonic mortality in the cow: its relationship with progesterone concentration. Veterinary Record 112, 517-521.
Sreenan, J.M. \& Diskin, M.G. (1987) Factors affecting pregnancy rate following embryo transfer in the cow. Theriogenology 27, 99-113.

Sreenan, J.M., Beehan, D. \& Mulvehill, P. (1975) Egg transfer in the cow: factors affecting pregnancy and twinning rates following bilateral transfers. Journal of Reproduction and Fertility 44, 77-85.

Sreenan, J.M., Gosling, J.P., Terqui, M. \& Thimonier, J. (1978) Diagnosis of twin-pregnancy and subsequent calving results following bilateral egg transfer in beef heifers. Theriogenology $9,103$.

Testart, J., Godard-Siour, C. \& du Mesnil du Buisson, F. (1975) Transvaginal transplantation of an extra egg to obtain twinning in cattle. Theriogenology 4, 163-168.

Utsumi, K., Katoh, H. \& Iritani, A. (1988) Developmental ability of bovine follicular oocytes matured in vitro and cultured in rabbit oviducts. Theriogenology 25, 218.

Xu, K.P., Pollard, J.W., Rorie, R.W., Plante, L., King, W.A. \& Betteridge, K.J. (1990) Pregnancy rates following transfer of bovine embryos produced by in vitro maturation, fertilization and co-culture. Theriogenology 33, 351.

Yang, N.S., Duff, R., Lu, K.H. \& Polge, C. (1991) Effect of storage temperature and time on the viability of bovine embryos produced in vitro. Theriogenology 35, 297.

Received 18 March 1991 